The Journal of Animal \& Plant Sciences, 30(4): 2020, Page: 913-922

ISSN (print): 1018-7081; ISSN (online): 2309-8694

\title{
MOLECULAR STUDY OF CBF AND WCOR14 GENES IN SELECTED SUGARCANE CULTIVARS AND ITS WILD RELATIVE SACCHARUM SPONTANEUM L.
}

\author{
S. U. Rehman ${ }^{1}$, Y. Que 2 , S. Khan ${ }^{1}$, E. Novaes ${ }^{3}$, Inamullah ${ }^{1}$ and K. Muhammad ${ }^{1 *}$ \\ ${ }^{1}$ Department of Genetics, Hazara University, Mansehra, 21300- Khyber Pakhtunkhwa Pakistan \\ ${ }^{2}$ Key Lab of Sugarcane Biology and Genetic Breeding, Ministry of Agriculture, Fujian Agriculture and Forestry \\ University Fuzhou, 350002-Fujian Province P R China. \\ ${ }^{3}$ Department of Biology, Universidade Federal de Lavras, Av. Central, s / n Campus Universitário, 37.200-000 - Lavras, \\ MG - Brazil \\ Corresponding Author's:Email: khushisbs@yahoo.com
}

\begin{abstract}
Abiotic factors severely affect, alter and limit the yield and quality of the plants. Among them, a significant stress to plant growth and quality is given by cold or low temperature. In order to minimize or localize the cold stress, plants adopt mechanisms in the form of elevated expression levels of cold responsive genes. In the present study, expression of cold responsive genes in sugarcane cultivars namely SPSG-394, CP-77400 and CP-851491 was performed along with expression analysis of these genes in wild sugarcane Saccharum spontaneum L. Expression of the stress responsive genes was detected through performing a cold stress experiment at $4{ }^{\circ} \mathrm{C}$ for 0,12 and 24 hours treatment. Tissues subsequent to stress treatment were collected and cryopreserved at $-80 \mathrm{C}$ for RNA extraction. Quantification of expression levels of stress responsive genes namely $C B F 1, C B F 2, C B F 3$ and $W C O R 14$ was performed with the help of semi-quantitative RT-PCR (reverse transcriptase polymerase chain reaction). The results indicated that $C B F 1, C B F 2$ and $C B F 3$ were abundantly expressed in all three sugarcane cultivars whereas their expression was higher in $S$. spontaneum $\mathrm{L}$ than in their commercial counterparts. Expression of the gene WCOR14 was seen to be higher in both commercial and sugarcane wild relative. Those amplified products were sequenced and then aligned using Basic Local Alignment Tool (BLAST) at NCBI, which demonstrated that genes $C B F 1, C B F 3$ and $W C O R 14$ had conserved domains with other known stress-responsive genes like DREB and CO14. However, $C B F 2$ encoded an uncharacterized protein and a conserved domain (gypsy type transposon). From all the above, we can conclude that the expression quantities of the stressresponsive genes were elevated in sugarcane cultivars SPSG-394 and CP-851491 exposed to cold stimuli and this factor could be contributive towards their ability to withstand higher cold stress.
\end{abstract}

Key words: Sugarcane, Cold responsive genes, Abiotic stress, expression profile and BLAST.

https://doi.org/10.36899/JAPS.2020.4.0107

Published online April 25, 2020

\section{INTRODUCTION}

Abiotic factors considerably limit and restrain the qualitative and quantitative aspects of the plant yield. Cold stress, a significant abiotic factor, poses a great challenge of tolerance and adjustment for plants. Low temperature (LT) reaching chilling and freezing levels works negatively on the growth seasons and restrains the geographical distribution of a myriad of crops. Sugarcane, an economically beneficial crop, is particularly considered to be prone to cold. The magnitude of the negative impact of LT on sugarcane is dependent upon various factors including duration and severity of cold stress, the time gap and temperature variation between the harvesting and freezing events, which ultimately results in economic losses and disturbed crop cycles (Xin and Browse, 2000; Ambika et al., 2016). Plants thus tend to improve molecular and physiological mechanisms to resist and diffuse the potential harm of cold temperature (Ding et al., 2019) and finally the resistance of cultivars post to freezing (Tai and Lentini, 1998).

The response of plants to cold stress is a complex process that involves many physiological and biochemical modifications. The expression of genes and protein metabolites in response of cold stress has been reported (Miura and Furumoto, 2013). In water stress phytohormone abscisic acid (ABA) and cold responsive genes are expressed. Several genes are expressed in dehydration during water stress and cold stress, the $\mathrm{ABA}$ biosynthesis lead to the expression of these cold responsive genes (Liu et al., 1998). The pathways of cold responsive genes in $\mathrm{ABA}$ dependent cold and drought stress have been described by Yamaguchi-Shinozaki and Shinozaki (1994); Gilmour et al. (1998); Liu et al. (1998). Identification of three transcription factors $(C B F 1, C B F 2$ and $C B F 3)$ from Arabidopsis has shown the direct evidence of ABA dependent pathways. These transcription factors encode protein containing AP2 DNA-binding motif (Medina et al., 1999). The CBF1, 
$C B F 2$ and $C B F 3$ (transcription factors) are not induced during exogenous ABA pathway; therefore this was suggested that these transcription factors participate during induced ABA pathway (Yamaguchi-Shinozaki and Shinozaki, 1994; Seki et al., 2001). (CBF/DREB) Crepeat/ dehydration responsive element binding factors play a role in improving plant cold stress resistance and recognize the CRT/DRE elements of cold regulated genes promoter region (Vazquez-Hernandez et al., 2017).

During abiotic stress like cold, salinity and drought these transcription factors bind to the dehydration elements/C-repeat (DRE/CRT) of the stress resistance genes and enhance the expression of these stress resistance genes (Liu et al., 1998). In nonacclimated transgenic Arabidopsis plant, the constitutive overexpression of the $C B F 1$ and $C B F 3$ induces the expression of other cold inducible genes increasing the tolerance of the plant to chilling and freezing stress (Gilmour et al., 2000). In sorghum fifteen potential candidate reference genes recently have been analyzed and reviewed in tissue (seedling, leaves, roots and, mature seed and panicles) treated with various abiotic stresses (cold, salt, dehydration and ABA stress). The amplification level of the best ranked reference genes, namely, SbHSF5 and SbHSF13 have been assayed (Sudhakar-Reddy et al., 2016). The cold responsive gene, including COR15a, (Artus et al., 1996), alfalfa Cas15 (Monroy et al., 1993) and wheat WCOR14, WCS120 (Houde et al., 1992) have been reported. The expression of cold responsive genes has been shown to be critical for both cold acclimation and chilling tolerance in plants (Thomashow, 1999). ). Moreover, in barley leaves cold induced genes have been identified using annealing control primer based approach (Lee et al., 2019).

Recently, the molecular level analysis in sugarcane during stress have been conducted to understand the mechanism of cold responsive genes (Yang et al., 2016; Rehman et al., 2019). Further high throughput illumine sequencing method and transcriptome profiling of $S$. sponteaneum sugarcane commercial cultivars have been performed during cold stress to view insight of molecular expression in the genome at transcriptome level (Dharshini et al., 2016; Shiyun et al., 2018) However a specific study of transcriptions factors and WCOR 14 genes expression in sugarcane has not been carried out yet. Therefore, in the current study, we report the expression activity of $C B F S$ transcription factors and WCOR14 genes in commercially grown Pakistani sugarcane cultivars and its wild relatives Saccharum spontaneum L.

\section{MATERIALS AND METHODS}

Plant material/Sample collection: The plant material for this research work was collected from Sugarcane Crop Research Institute Mardan, Khyber Pakhtunkhwa Pakistan. Three commercially grown sugarcane cultivar namely SPSG-394, CP-77400, CP-851491 based on resistance to cold stress and wild type Saccharum spontaneum L. was selected as control from cold region Murree, Punjab Pakistan. The plants were collected during maturing stage and were planted in the research field of Genetics Department Hazara University, Mansehra (Table. 1)

Table.1. Detail of selected sugarcane cultivars collected from Sugarcane Crop Research Institute Mardan and Saccharum spontaneum L. from Murree, Pakistan.

\begin{tabular}{llccccl}
\hline $\begin{array}{l}\text { Serial } \\
\text { No. }\end{array}$ & Cultivars & Year of Release & $\begin{array}{c}\text { Cane Yield } \\
\text { (t/ha) }\end{array}$ & CCS\% & Maturity & Cold Responses \\
\hline 1 & SPSG-394 & 2003 & 50.00 & 11.00 & Early & Cold tolerant \\
2 & CP-851491 & 1994 & 60.00 & 11.00 & Early & Cold tolerant \\
3 & CP-77400 & 1996 & 74.00 & 12.18 & Mid & Cold susceptible \\
4 & Saccharum Spontaneum L. & N/A & N/A & N/A & N/A & Cold tolerant \\
\hline
\end{tabular}

Cold stress treatment and RNA extraction: For RNA extraction, disease free plant samples were collected from the Research field of Department of Genetics Hazara University Mansehra, Pakistan. The grown plant tissue was cut into pieces having at least one bud and then kept in running water to remove impurities and to promote spouting. The samples were then grown in small pots and incubated in the incubator $\left(27^{\circ} \mathrm{C}\right.$ and $60 \%$ humidity). After two weeks the new plant grown from buds were immediately transferred for cold stress $\left(4^{\circ} \mathrm{C}\right)$. Four biological replicates and three treatments were adjusted in this experiment. Tissues were collected from the cold treated samples at 0 hours; 12 hours and 24 hours treatment and were immediately stored at $-80^{\circ} \mathrm{C}$ before RNA extraction.

The RNA was extracted from the collected leaf tissue from the samples by using Pure Link RNA mini Kit (Cat\# 12183018A) following the manufacturers protocol. The extracted RNA was checked on $1 \%$ Agarose Gel (Figure 1). 


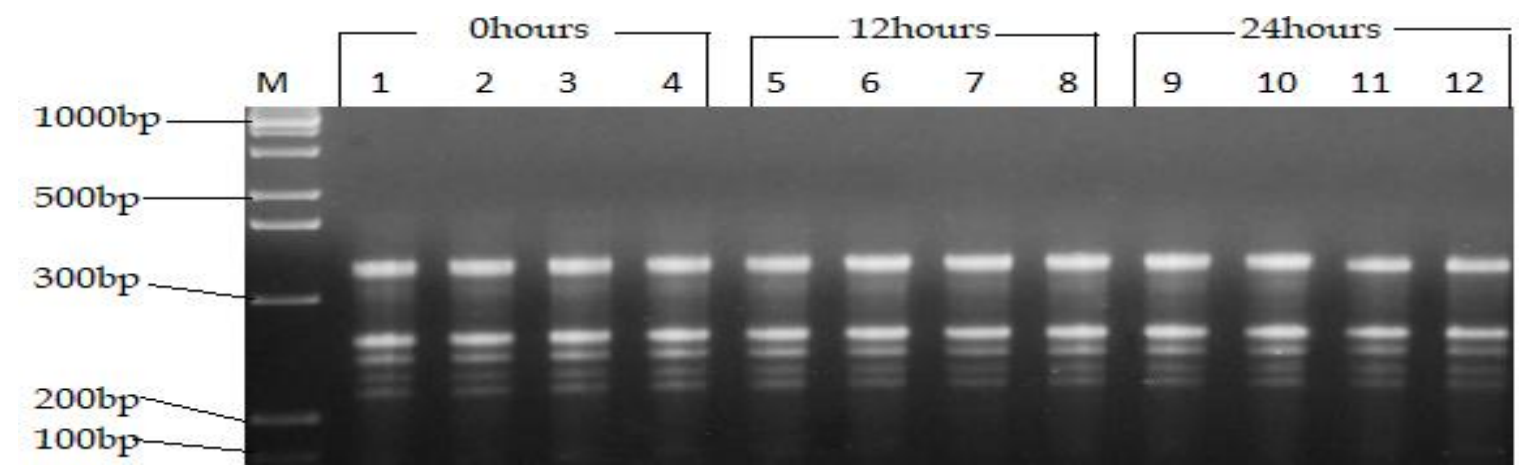

Figure 1. Total RNA extracted from sugarcane cultivars and Saccharum spontaneum L. Lanes: 1, 2, 3 and 4 represent SPSG-394, CP-851491, CP-77400 and Saccharum spontaneum L. Lanes: 5, 6, 7 and 8 represent SPSG-394, CP-851491, CP-77400 and Saccharum spontaneum L. Lanes: 9, 10, 11 and 12 represent SPSG394, CP-851491, CP-77400 and Saccharum spontaneum L. M represents 1Kb+ DNA ladder (Fermentas; cat\# SM0331).

cDNA Synthesis:The first strand cDNA was synthesized from the extracted RNA by using RevertAid First Strand cDNA synthesis kit (Cat\# K1622). First 4 4 RNA was taken in the RNAase free PCR tubes and then $1 \mu \mathrm{l}$ of Oligo (dt) was added to each tube. The RNAs free (DEPC) water $7 \mu 1$ was added to the tube containing the RNA template and Oligo (dt) was mixed gently. The tubes were incubated at $65^{\circ} \mathrm{C}$ for 5 minutes. After incubation, the samples were kept on ice and $4 \mu \mathrm{l}$ of $5 \mathrm{x}$ reaction buffer was added and $1 \mu 1$ of RiboLock RNAase inhibitor, $2 \mu 1$ of dNTP and $1 \mu l$ RevertAid M-Mul V RT. The solution was gently mixed well and incubated at $42^{\circ} \mathrm{C}$ for 60 minutes and terminated the reaction by heating at $70^{\circ} \mathrm{C}$ for 5 mints. After incubation, the cDNA was kept at $-20^{\circ} \mathrm{C}$ before use. The synthesized CDNA product was then used in PCR with gene specific primers (Figure 2).

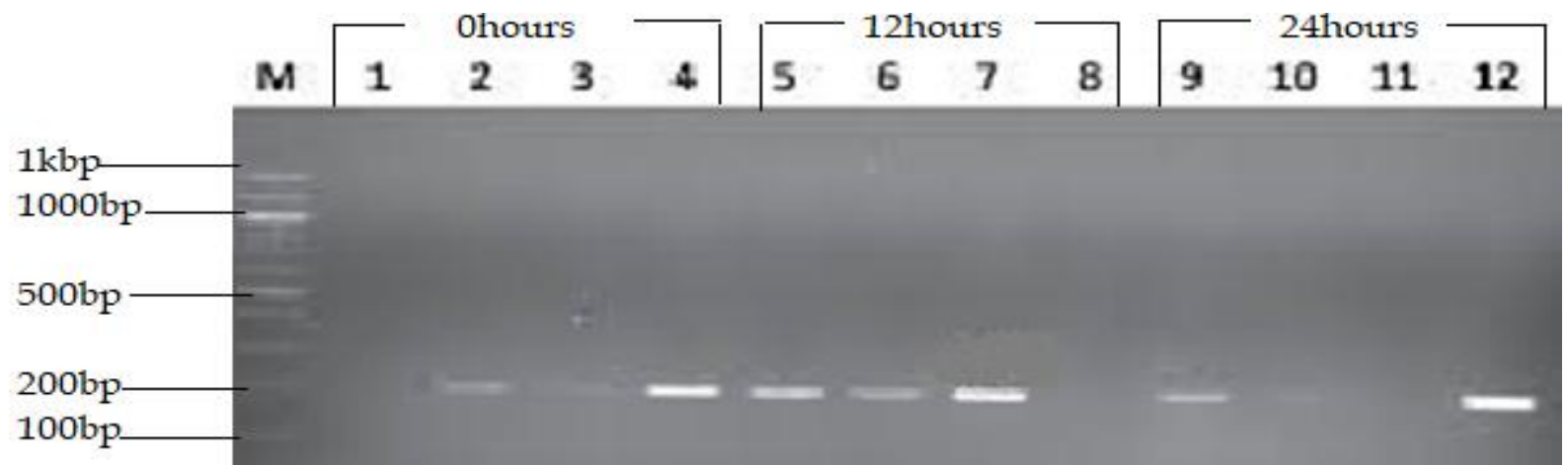

Figure 2. Synthesized cDNA of cold treated sugarcane cultivars and Saccharum spontaneum L. Lanes: 1, 2, 3 and 4 represent SPSG-394, CP-851491, CP-77400 and Saccharum spontaneum L. Lanes: 5, 6, 7 and 8 represent SPSG-394, CP-851491, CP-77400 and Saccharum spontaneum L. Lanes: 9, 10, 11 and 12 represent SPSG-394, CP-851491, CP-77400 and Saccharum spontaneum L. M represents 1Kb+ DNA ladder (Fermentas; cat\# SM0331).

Gene selection and Designing of Primers: Selected cold responsive genes (CBFs and WCOR14) were selected from public database and reported literature of
Andropogoneae tribe. Further, primers were designed for the conserved regions of the genes (Table 2) and these primers were synthesized from Macrogen Korea.

Table. 2. Detail of primers used in this study.

\begin{tabular}{lllll}
\hline Serial No. & Gene Name & Forward primers & Reverse primers & TM \\
\hline 1 & CBF1 & CAGCCTTAACAAGACGCACA & CCGTTTGCTAGCTTTTGAGC & $58^{\circ} \mathrm{C}$ \\
2 & CBF2 & GTGTGGCCAGAGGAGGAGTA & CGAGCCAGATCCTGGAGTAA & $58^{\circ} \mathrm{C}$ \\
3 & CBF3 & CGCGCTCTGGAGCTACTACT & GGGAAGACGACAAGAACAGC & $58^{\circ} \mathrm{C}$ \\
4 & WCOR 14 & CTTCTTCTTCCGTGCTGCTC & TCGCAAAGAACAAAACACCA & $58^{\circ} \mathrm{C}$ \\
\hline
\end{tabular}


Semi quantitative Polymerase Chain Reaction: Thermo scientific PCR kit (Catalog \#EP0402) was used for the amplification of selected genes in the cDNA of sugarcane cultivars and Saccharum spontaneum L.

Agarose Gel electrophoresis of PCR amplified product: The semi quantitive PCR amplified products were further confirmed by $1.5 \%$ agarose gel and the amplicon size was compared with $1 \mathrm{~Kb}$ DNA marker.

Data analysis: The transcription factor $(C B F 1, C B F 2$ and $C B F 3$ ) and $W C O R 14$ genes in the stress treated cDNA were further confirmed by sequencing. The samples were sent to the Beijing Genomic Institute, China for sequencing. The optimized sequences of sugarcane cultivars and Saccharum spontaneum L. were analysed by using NCBI protein BLAST and conserved domain search.

\section{RESULTS}

Amplification of $C B F s(C B F 1, C B F 2$ and $C B F 3)$ and WCOR14 genes from cDNA: For the amplification of targeted cDNA using primers of transcription factors, namely $C B F 1, C B F 2, C B F 3$ and $W C O R 14$ gene, various thermocyclic conditions were used to test desired amplicon (Figure 3, 4, 5 and 6).

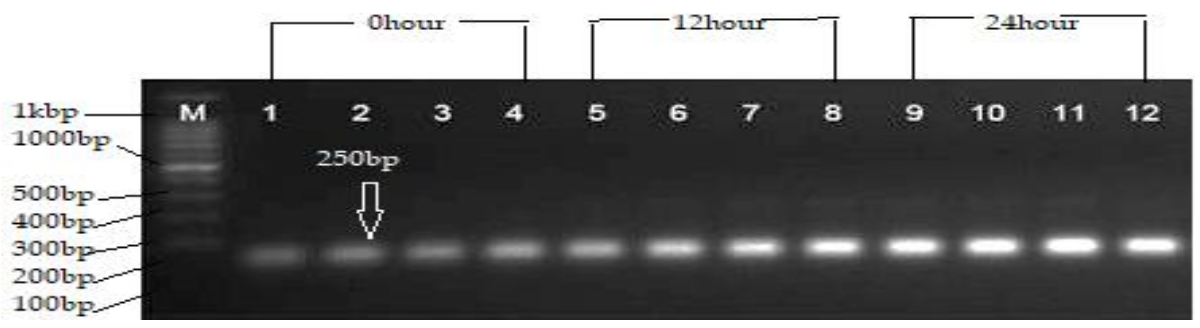

Figure 3. Semi quantitative PCR amplified product of cold tolerance genes (CBF1) from cDNA of cold treated sugarcane cultivars and Saccharum spontaneum L. Lanes: 1, 2, 3 and 4 represent SPSG-394, CP-77400, CP-851491 and Saccharum spontaneum L. Lanes: 5, 6, 7 and 8 represent SPSG-394, CP-77400, CP851491 and Saccharum spontaneum L. Lanes: 9, 10, 11 and 12 represent SPSG-394, CP-77400, CP851491 and Saccharum spontaneum L. M represents DNA 1Kb+ ladder (Fermentas; cat\# SM0331).

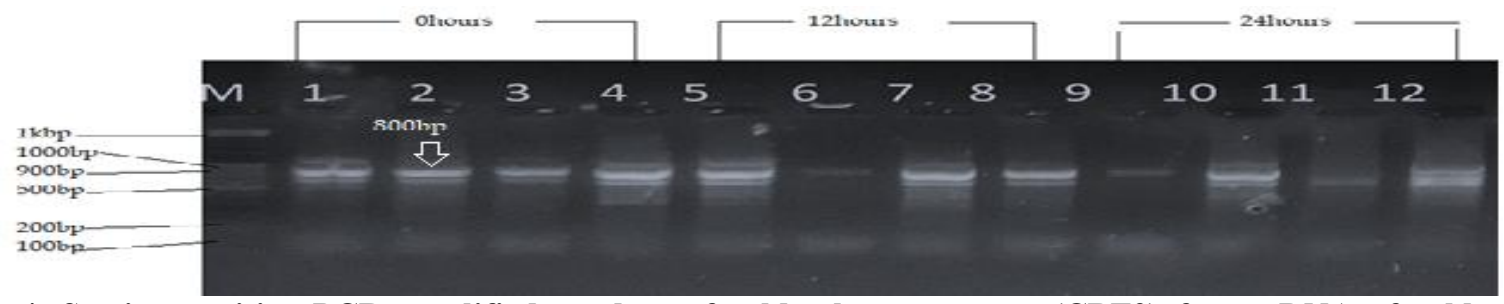

Figure 4. Semi quantitive PCR amplified product of cold tolerance genes (CBF2) from cDNA of cold treated sugarcane cultivars and Saccharum spontaneum L. Lanes: 1, 2, 3 and 4 represent SPSG-394, CP-77400, CP-851491 and Saccharum spontaneum L. Lanes: 5, 6, 7 and 8 represent SPSG-394, CP-77400, CP851491 and Saccharum spontaneum L. Lanes: 9, 10, 11 and 12 represent SPSG-394, CP-77400, CP851491 and Saccharum spontaneum L. M represents 1Kb+ DNA ladder (Fermentas; cat\# SM0331).

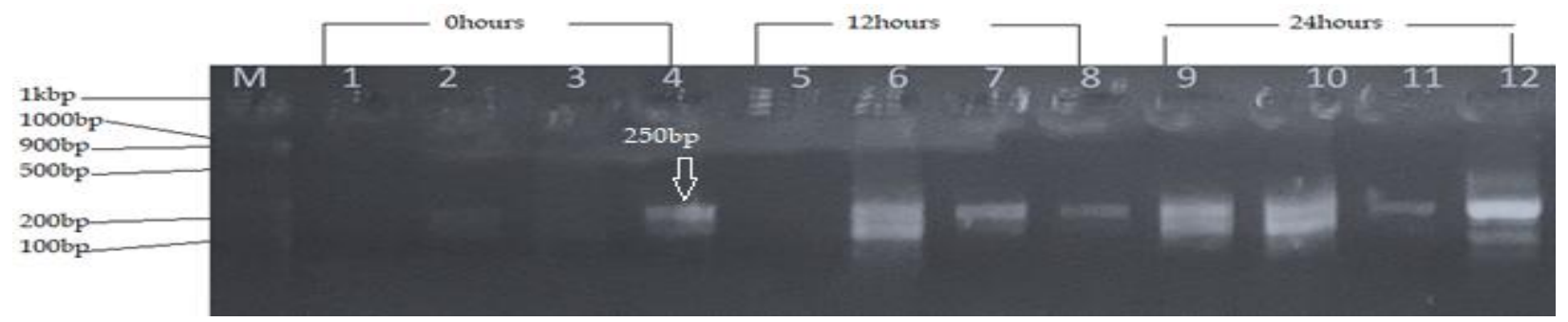

Figure 5. Gel electronic photograph of PCR amplified product of CBF3 gene. $M$ is $1 \mathrm{~Kb}+$ marker while samples from 1 to sample 4 are leaf tissue extracted before cold stress means at ${ }^{0} \mathrm{C}$. From sample 5 to sample 8 the tissue extracted after 12 hour cold stress. From sample 9 to sample 12 are 24 hours cold treated samples. The sample 1, 5, 9 are CP 77-400. Sample 2, 6, 10 are SPSG 394. Sample 3, 7, 11 are CP85-1491 and sample 4, 8, and 12 are Saccharum spontaneum $L$ respectively 


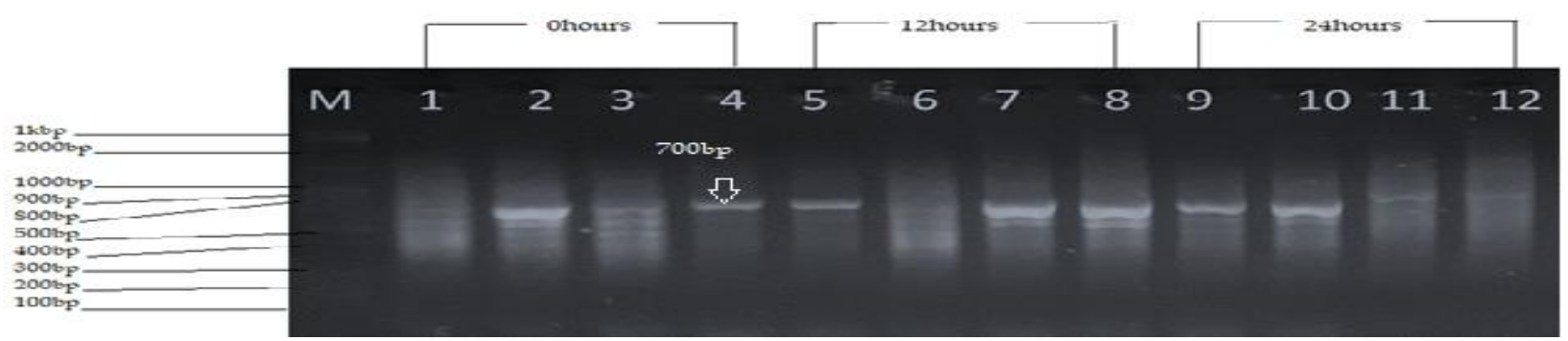

Figure 6. Semi quantitive PCR amplified product of cold tolerance genes (WCOR14) from cDNA of cold treated sugarcane cultivars and Saccharum spontaneum L. Lanes: 1, 2, 3 and 4 represent SPSG-394, CP-77400, CP-851491 and Saccharum spontaneum L. Lanes: 5, 6, 7 and 8 represent SPSG-394, CP-77400, CP851491 and Saccharum spontaneum L. Lanes: 9, 10, 11 and 12 represent SPSG-394, CP-77400, CP851491 and Saccharum spontaneum L. M represents 1Kb+ DNA ladder (Fermentas; cat\# SM0331).

\section{Analysis}

Expression study of selected genes in cDNA: The expression study of selected cold tolerance genes, in the cDNA of selected sugarcane cultivars and Saccharum spontaneum L. were observed from the thickness of the specific amplicon of the genes with respect to each cold stress time point from Agarose gel. Among the selected
COR genes, the expression of $C B F s$ and WCOR14 genes were found higher in the cDNA of all selected sugarcane cultivars and Saccharum spontaneum L. but the expression of $C B F 3$ gene at 0 hours treatment was observed higher only in wild relative of sugarcane Saccharum spontaneum L. (Table 3).

Table 3. The number of amplicon of CBFs and WCOR14 genes in each sugarcane cultivar and wild relative Saccharum spontaneum $\mathrm{L}$. with cold stress treatment time point.

\begin{tabular}{|c|c|c|c|c|}
\hline Serial no. & Gene name. & Sample name & Cold stress time point & Expression level \\
\hline \multirow[t]{12}{*}{1} & \multirow[t]{12}{*}{$C B F 1$} & \multirow[t]{3}{*}{ SPSG-394 } & 0 hours & Low \\
\hline & & & 12 hours & High \\
\hline & & & 24hours & High \\
\hline & & \multirow[t]{3}{*}{ CP-77400 } & 0 hours & Low \\
\hline & & & 12 hours & High \\
\hline & & & 24 hours & High \\
\hline & & \multirow[t]{3}{*}{ CP85-1491 } & 0 hours & Low \\
\hline & & & 12 hours & High \\
\hline & & & 24 hours & High \\
\hline & & \multirow[t]{3}{*}{ Saccharum spontaneum L. } & 0 hours & Low \\
\hline & & & 12 hours & High \\
\hline & & & 24 hours & High \\
\hline \multirow[t]{12}{*}{2} & \multirow[t]{12}{*}{$C B F 2$} & \multirow[t]{3}{*}{ SPSG-394 } & 0 hours & High \\
\hline & & & 12 hours & High \\
\hline & & & 24 hours & High \\
\hline & & \multirow[t]{3}{*}{ CP-77400 } & 0 hours & High \\
\hline & & & 12 hours & High \\
\hline & & & 24 hours & High \\
\hline & & \multirow[t]{3}{*}{ CP85-1491 } & 0 hours & High \\
\hline & & & 12 hours & High \\
\hline & & & 24 hours & High \\
\hline & & \multirow{3}{*}{ Saccharum spontaneum L. } & 0 hours & High \\
\hline & & & 12 hours & High \\
\hline & & & 24 hours & High \\
\hline \multirow[t]{5}{*}{3} & \multirow{5}{*}{$C B F 3$} & \multirow{3}{*}{ SPSG394 } & 0 hours & Very low \\
\hline & & & 12 hours & Very low \\
\hline & & & 24 hours & High \\
\hline & & \multirow{2}{*}{ CP-77400 } & 0 hours & High \\
\hline & & & 12 hours & High \\
\hline
\end{tabular}




\begin{tabular}{|c|c|c|c|c|}
\hline & & & 24 hours & High \\
\hline & & CP-851491 & 0 hours & Very low \\
\hline & & & 12 hours & High \\
\hline & & & 24 hours & High \\
\hline & & Saccharum spontaneum L. & 0 hours & High \\
\hline & & & 12 hours & High \\
\hline & & & 24 hours & High \\
\hline 3 & WCOR14 & SPSG-394 & Ohours & Maximum \\
\hline & & CP-77400 & 12hours & High \\
\hline & & CP-851491 & 24hours & High \\
\hline & & Saccharum spontaneum L. & & \\
\hline
\end{tabular}

Analysis of Sequences data: For further investigation, the amplified $C O R$ genes ( $C B F S$ and WCOR14) were sequenced. Furthermore, the successful sequences of selected $C O R$ genes in selected sugarcane cultivars and Saccharum spontaneum L. were analysed by using NCBI Protein BLAST (Basic Local Alignment Sequence tool) for comparison of already available data. Analysis of the successful sequences of selected $C O R$ genes showed that these COR genes (CBFs and WCOR14) encode cold and other abiotic stress responsive protein (Figure 7, 8, 9 and $10)$.

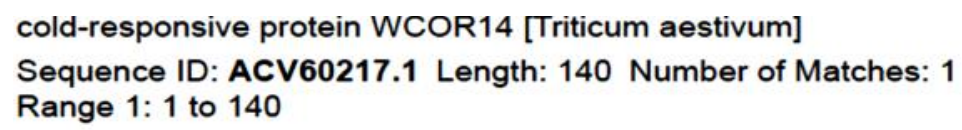

Figure 7. The protein blast of WCOR14 genes of sugarcane and Saccharum spontaneum L. were shown identification with Wheat protein, which is responsible for cold stress.

CBF1 interacting corepressor [Zea mays]

Sequence ID: ONM16301.1 Length: 125 Number of Matches: 1

Range 1: 35 to 109

\begin{tabular}{|c|c|c|c|c|c|c|c|}
\hline \multicolumn{2}{|l|}{ Score } & \multirow{2}{*}{ Expect } & \multicolumn{2}{|l|}{ Method } & Positives & Gaps & Frame \\
\hline 112 bits & $(281)$ & & Compositior & nal matrix adjust. & $75 / 75(100 \%)$ & $0 / 75(0 \%)$ & +2 \\
\hline Query & 359 & \multicolumn{5}{|c|}{$\begin{array}{l}\text { PSQTDGSFHSPEWHAARLASLNKTHTLTWeefkkkqkeeelkrgeleADKDKMMREYRAQ } \\
\text { PSQTDGSFHSPEWHAARLASLNKTHT+TWEEFKKKQKEEELKRGELEADKDKMMREYRAQ }\end{array}$} & 538 \\
\hline Sbjct & 35 & \multicolumn{5}{|c|}{ PSQTDGSFHSPEWHAARLASLNKTHTVTWEEFKKKQKEEELKRGELEADKDKMMREYRAQ } & 94 \\
\hline Query & 539 & \multirow{2}{*}{\multicolumn{3}{|c|}{$\begin{array}{l}\text { LDAERAQKLANGRNH } \\
\text { LDAERAQKLANGRNH } \\
\text { LDAERAQKLANGRNH }\end{array}$}} & & & \\
\hline Sbjct & 95 & & & & & & \\
\hline
\end{tabular}

Figure 8. The protein blast of CBF1 gene of sugarcane and Saccharum spontaneum L showed similarities with CBF1 interacting corepressor (Zea mays). 
uncharacterized protein LOC110430230 [Sorghum bicolor] Sequence ID: XP_021303183.1 Length: 314 Number of MatcheS: 1 Range 1: 86 to 207

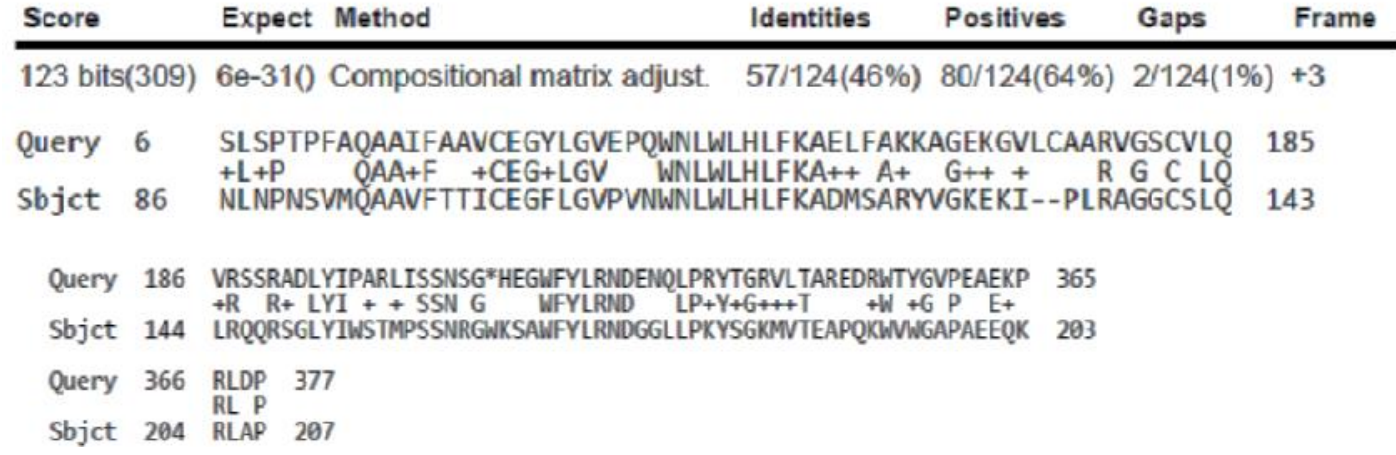

Figure. 9. The protein blast of $C B F 2$ gene of selected sugarcane cultivars and Saccharum spontaneum $\mathrm{L}$ showed similarities with uncharacterized protein LOC110430230 (Sorghum bicolor).

DREB-like protein [Zea mays]

Sequence ID: AAN76804.1 Length: 267 Number of Matches: 1

Range 1: 1 to 267

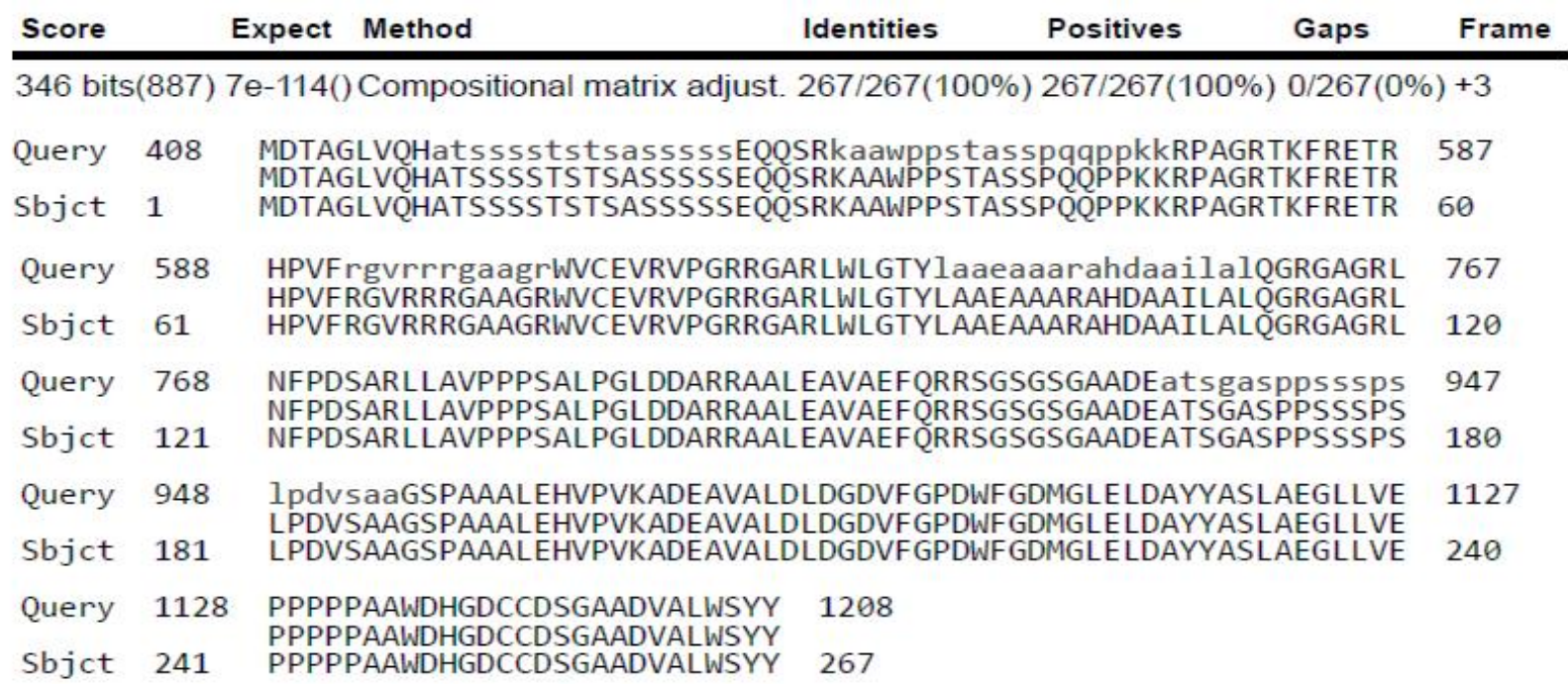

Figure 10. The protein blast of $C B F 3$ genes of selected sugarcane cultivars and Saccharum spontaneum $\mathrm{L}$ showed similarities with DREB protein (Zea mays) responsible for cold stress.

Conserved Domain: A gypsy type retrotransposons Conserved domain has been detected during conserved domain search in $C B F 2$ gene sequence (Figure 11). The mechanism of gypsy type transposase is like copy pastes these families of plant genes revolved close association with gypsy type transposon and have an important role in the regulation of genes.

\section{Graphic Summary}

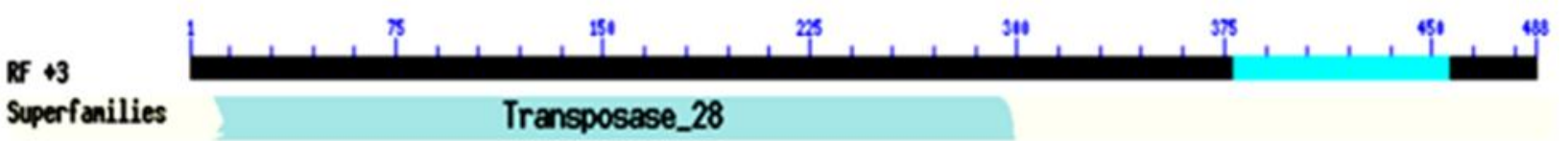

Figure 11. The $C B F 2$ gene sequence of selected sugarcane cultivar and Saccharum spontaneum L. detect putative conserved domains during (gypsy type transposase_28) Conserved Domain Search (CDS) in NCBI. 
Mechanism of transcription factors: When plant expose to cold temperature, the plant develop many mechanisms including expression of genes. Although the initial response of plant sensor is the expression of transcription factor (CBF1, CBF2 and CBF3), these transcription factors bind to the $\mathrm{C}$-repeats in the promoter region of the cold responsive genes and enhance the transcription activity of COR genes.

\section{DISCUSSION}

Cold temperature every year causes a significant loss in the quality and production of many economically and industrially important plants worldwide. Sugarcane is derived by the interbreeding of Saccharum species and is one of the major commercially growing crops in all parts of the globe, approximately more than 120 countries and is mostly considered as a plant sensitive to low temperature (Tai and Lentini, 1998). Low temperature adversely affects the growth, development, and productivity of the plants; diverse plant species tolerate cold stress to a varying degree, which depends on reprograming gene expression to modify their metabolism, growth and physiology (Viswanathan et al., 2010). Many studies have been carried out recently on the expression analysis of cold responsive genes in sugarcane during cold stress, miRNAs (candidates genes) expressed during cold stress in sugarcane have been analyzed in sugarcane the results showed that these genes help in the normalization during cold stress (Yang et al., 2016; Rehman et al., 2019). Park et al. (2015) performed transcriptomic analysis of cold responsive genes in (cold susceptible) sugarcane cultivar CP72-1210 and Saccharum spontaneum TUS05-05 (cold tolerant) using sugarcane assembled sequence (SAS) from SUCEST-FUN database. The results showed that total of 35,340 and 34,698 SAS genes were expressed before and after chilling stress respectively. More than 6000 genes were differentially expressed in each genotype after chilling stress. Moreover, many studies have been reported, on expression analysis of cold responsive genes during cold stress in sugarcane. However a specific study of transcription factors $(C B F s)$ and WCOR 14 gene expression in sugarcane was not carried yet. Therefore, the main objective of this study was to investigate the expression analysis of cold tolerance gene $(C B F 1, C B F 2$ and $C B F 3)$ and WCOR14 genes in the cDNA of cold treated sugarcane. Initially, three commercially grown Pakistani sugarcane cultivars namely, SPSG-394, CP-851491 and CP-77400 were selected based on cold response in the field. Further, one wild type of sugarcane relative Saccharum spontaneum L. were also included and collected from cold area Murree, Pakistan.

The response of plants to cold stress is a complex process involving many physiological and biochemical modifications. The expression of genes and protein metabolites in the response of cold stress has been reported (Miura and Furumoto, 2013). Transcription factors (CBF1,
$C B F 2$ and $C B F 3$ ), encode protein containing AP2 DNAbinding motif (Medina et al., 1999). During abiotic stresses like cold, salinity and drought, these transcription factors bind to the dehydration elements/C-repeat (DRE/CRT) of the stress resistance genes (Liu et al., 1998) and induces the expression of other cold inducible genes increasing the tolerance of the plant to chilling and freezing stress (Gilmour et al., 2000). In this study $C B F 1, C B F 2$ and $C B F 3$ genes were analysed from the cDNA of cold stress treated sugarcane cultivars and Saccharum spontaneum L. at three cold stress treatment levels ( 0,12 and 24 hours). Based on the result profile $C B F S$ genes were expressed in all investigated sugarcane cultivars and Saccharum spontaneum $\mathrm{L}$. In our result $C B F 1, C B F 2$ and $C B F 3$ genes were analysed in the cold stress treated sugarcane cultivars and Saccharum spontaneum L. at three cold stress treatment levels 0, 12 and 24 hours. Based on the expression profile CBFs genes were expressed in all investigated sugarcane cultivars and Saccharum spontaneum L. Although, the $C B F 3$ gene expression level was observed very low at 0 hours stress treatment level in selected sugarcane cultivars while observing higher in Saccharum spontaneum L. (Table 3).In wheat the expression of WCOR14 gene is linked to low temperature specificity, it is turned over during the accumulation period appeared to be rapid and the expression remains at a high steady state level, and encode (COR14) protein, which is a polypeptide of $14 \mathrm{kDa}$ which accumulate under the condition of low temperature (Tsvetanov et al., 2000). The expression level of WCOR14 gene was observed higher in all selected sugarcane cultivars and Saccharum spontaneum L. The sequence analysis of CBFs and WCOR14 genes of investigated sugarcane cultivars and Saccharum spontaneum L., showed that these genes encode stress responsive protein, $C B F 1$ encode $C B F 1$ interacting corepressor, $C B F 2$ encode uncharacterized protein, $C B F 3$ encode DREB and WCOR14 encode CO14 cold responsive protein. Further, the CBF2 sequences during protein BLAST detect a conserved domain (gypsy type transposon) help in gene regulation.

Conclusion: In this research work we studied three sugarcane cultivars of Khyber Pakhtunkhwa region of Pakistan. The selected sugarcane cultivars were selected by suggestion of farmers because this is the first study report on sugarcane cold tolerant cultivars of Khyber Pakhtunkhwa Pakistan. There is no specific Pakistani cold tolerant sugarcane cultivar identified till now. In this research, the CBFs and WCOR14 genes were characterized in Saccharum spontaneum L. While in selected sugarcane cultivars SPSG-394 and CP-851491 mostly CBF and WCOR 14 genes were expressed. In CP 77-400, less number of genes was optimized. So the SPSG-394 and CP851491 are cold tolerant and they have the ability to resist to cold stress. 
This study was helpful for identification of cold tolerant cultivars. Transcriptome sequencing and gene expression study also led to better identification of resistant cultivars. These techniques could be used for identification and breeding of cold tolerant cultivars.

Acknowledgments: The authors thankful to Higher Education Commission of Pakistan for supporting and providing funding for this study and also thankful to Sugarcane Crop Research Institute Mardan, Khyber Pakhtunkhwa for providing plant Martial for the experiment.

\section{REFERENCES}

Ambika, S., I.M. Nambi, and J. Senthilnathan (2016). Low temperature synthesis of highly stable and reusable $\mathrm{CMC}-\mathrm{Fe} 2+\mathrm{n}$ ZVI catalyst for the elimination of organic pollutants. J. Chem. Eng. 28(9): 544-553.

Artus, N.N., M. Uemura, P.L. Steponkus, S.J. Gilmour, C.T. Lin, and M.F. Thomashow (1996). Constitutive expression of the cold regulated Arabidopsis thaliana COR 15a gene avects both chloroplast and protoplast freezing tolerance. Proc. Natl. Acad. Sci. USA. 93: 13404-13409.

Dharshini, S., M. Chakravarthi, V. M. Manoj, M. Naveenarani, R. Kumar, M. Meena, B. Ram and C. Appunu (2016). De novo sequencing and transcriptome analysis of a low temperature tolerant Saccharum spontaneum clone IND 001037. J. Biotechnol. 231:280-294.

Ding, Y., Y. Shi, and S. Yang (2019). Advances and challenges in uncovering cold tolerance regulatory mechanisms in plants. New. Phytologist. 222: 1690-1704.

Gilmour, S. J., A. M. Sebolt, M. P. Salazar, J. D. Everard and M. F. Thomashow (2000). Overexpression of the Arabidopsis CBF3 Transcriptional Activator Mimics Multiple Biochemical Changes Associated with Cold Acclimation. Plant Physiol. 124:1854-1865.

Gilmour, S.J., D.G. Zarka, E.J. Stockinger, M.P. Salazar, J.M. Houghton, and M.F. Thomashow (1998). Low temperature regulation of the Arabidopsis CBF family of AP2 transcriptional activators as an early step in cold-inducible COR gene expression. Plant. J. 16: 433-442

Houde, M., R.S. Dhindsa, and F. Sarhan (1992). A molecular marker to select for freezing tolerance in Gramineae. Mol. Gen. Genet. 234: 43-48.

Miura, K., and T. Furumoto (2013). Cold Signaling and Cold Response in Plants. Int. J. Mol. Sci. 14: 5312-5337. Doi: 10.3390/ijms14035312.

Lee, K.W., M.A. Rahman, Y. Song, H.C. Ji, G.J. Choi, K.Y. Kim, and S.H. Lee (2019). Cold stress- induced regulation of differentially expressed genes in barley (Hordeum vulgarel.) leaves. The J. Anim. Plant. Sci. 29(6): 1673-1679.

Liu, Q., M. Kasuga, Y. Sakuma, H. Abe, S. Miura, K. Yamaguchi-Shinozaki, and K. Shinozaki (1998). Two transcriptions factors, DREB1 and DREB2, with an EREBP/AP2 DNA binding domain separate two cellular signal transduction pathways in drought- and low-temperature-responsive gene expression, respectively, in Arabidopsis. Plant. Cell. 10: 1391-1406.

Medina, J., M. Bargues, J. Terol, M. Pe'rez-Alonso, and J. Salinas (1999). The Arabidopsis CBF gene family is composed of three genes encoding AP2 domain-containing proteins whose expression is regulated by low temperature but not by abscisic acid or dehydration. Plant. Physiol. 11: 463-469.

Monroy. A.F., Y. Castonguay, S. Laberge, F. Sarhan, L.P. Vezina, and R.S. Dhindsa (1993). A new coldinduced alfalfa gene is associated with enhanced hardening at sub-zero temperature. Plant. Physiol. 102: 873-879.

Park, J.W., T.R. Benatti, T. Marconi, Q. Yu, N. SolisGracia, V. Mora, et al. (2015). Cold Responsive Gene Expression Profiling of Sugarcane and Saccharum spontaneum with Functional Analysis of a Cold Inducible Saccharum Homolog of NOD26- Like Intrinsic Protein to Salt and Water Stress. PLoS. ONE. 10(5): e0125810. doi:10.1371/journal. pone.0125810.

Rehman, U.S., K. Muhammad, Y. Que, A.U. Rehman, E. Novaes, and S. Khan (2019). Presence of seventeen genes potentially involved in cold tolerance in sugarcane and Saccharum spontaneum genotypes. Int. J. Biosci. 14(1): 346355.

Seki, M., M. Narusaka, H. Abe. M. Kasuga, K. Yamaguchi-Shinozaki, P. Carninci, Y. Hayashizaki, and K. Shinozaki (2001). Monitoring the expression pattern of 1,300 Arabidopsis genes under drought and cold stress by using a full-length cDNA microarray. Plant. Cell. 13: 61-72.

Shiyun, T., Y. Litao, and L. Yangrui (2018). Compartive Analysis of Transcriptomes of different sugarcane varieties under low temperature stress. Biotechnol. Bull. 34(12): 116-124.

Sudhakar-Reddy, P., D. Srinivas-Reddy, K. Sivasakthi, P. Bhatnagar-Mathur, V. Vadez, and K.K. Sharma (2016). Evaluation of Sorghum [Sorghum bicolor (L.)] Reference Genes in Various Tissues and under Abiotic Stress Conditions for Quantitative Real-Time PCR Data Normalization. Front. Plant. Sci. 7: 529. Doi: 10.3389/fpls.2016.00529. 
Tai, P.Y.P., and R.S. Lentini (1998). Freeze damage of Florida sugarcane. 1st Ed. Sugarcane Handbook; Florida Cooperative Extension Service (University of Florida, Gainesville). 1-3 p

Thomashow, M.F. (1999). Plant cold acclimation: freezing tolerance genes and regulatory mechanism. Ann. Rev. Plant. Biol. 50: 571-599.

Tsvetanov, S., R. Ohno, K.Tsuda, S. Takumi, N. Mori, A. Atanassov, and C. Nakamura (2000). A coldresponsive wheat (Triticum aestivum L.) gene wcor14 identified in a winter-hardy cultivar Mironovska 808'.Genes. Genet. Syst. 75(1): 4957.

Vazquez-Hernandez, M., I. Romero, M.I. Escribano, C. Merodio, and M.T. Sanchez-Ballesta (2017). Deciphering the Role of CBF/DREB Transcription Factors and Dehydrins in Maintaining the Quality of Table Grapes cv.
Autumn Royal Treated with High CO2 Levels and Stored at 0_C. Front. Plant. Sci. 8: 1591.

Viswanathan, C., J.K. Zhu, and R. Sunkar (2010). Gene Regulation During Cold Stress Acclimation in Plants. Methods. Mol. Biol. 639: 39-55.

Xin, Z., and J. Browse. (2000). Cold comfort farm: the acclimation of plants to freezing temperatures. Plant. Cell. Environ. 23: 893-902.

Yamaguchi-Shinozaki, K., and K. Shinozaki (1994). A novel cis-acting element in an Arabidopsis gene is involved in responsiveness to drought, low temperature or high-salt stress. Plant. Cell. 6: 251.264.

Yang, Y., X. Zhang, Y. Chen, J. Guo, H. Ling, S. Gao, Y. Su, Y. Que, and L. Xu (2016). Selection of Reference Genes for Normalization of MicroRNA Expression by RT-qPCR in Sugarcane Buds under Cold Stress. Front. Plant. Sci. 7: 86. 